\title{
CUTANEOUS SUPERFICIAL MYIASIS: REPORT OF A RARE NOSOCOMIAL PARASITIC DISEASE CAUSED BY SARCOPHAGA SPP. (DIPTERA, SARCOPHAGIDAE)
}

\author{
Moreno Dutto', Michele Bertero² \\ ${ }^{1}$ Medical-Entomology Consultant, Azienda Ospedaliera S. Croce e Carle, Cuneo, Italy \\ ${ }^{2}$ Dermatology Unit, Azienda Ospedaliera S. Croce e Carle, Cuneo, Italy
}

\section{SUMMARY}

Flies of the genus Sarcophaga are known to cause myiasis in necrotic wounds and in anatomical cavities where fluids have collected. We present here the first case of external cutaneous myiasis by Sarcophaga larvae in the absence of skin ulcerations or necrosis. The host in this case was a geriatric patient with limited motor and neurological capacity who lives in a nursing home.

Of particular importance is that Sarcophaga is capable of causing myiasis even in the absence of cutaneous infections or significant stasis of fluids or secretions and that the larvae can cause damage in otherwise healthy tissue.

Key words: superficial myiasis, nosocomial myiasis, Sarcophaga, geriatric patient

Address for correspondence: M. Dutto, Medical-Entomology Consultant, Azienda Ospedaliera S. Croce e Carle, Via M. Coppino, 12100 Cuneo, Italy. E-mail: dutto.moreno@tiscali.it

\section{INTRODUCTION}

The term myiasis, first used by Hope in 1840 (1), refers to human and animal parasitical diseases caused by fly larvae. The definition in use today is by Zumpt (2). Cases of myiasis in humans appear fairly infrequently with most occurring in tropical areas due to the presence of species which cause specific myiasis $(3,4)$, and in developing countries where socio-economic factors create health and hygiene conditions conducive to parasitic situations for specific and semispecific myiasis (5).

Species from the genus Sarcophaga are responsible semispecific and accidental myiasis in humans (6) and animals (7). In the literature there are reports of Sarcophaga spp. larvae infestation in the host's intestines (8), cutaneous lesions due to trauma and/ or ulcerations $(9,10)$ as well as auricular $(11)$, oral $(12)$, ocular (13), nasal (14), and genital (15) infestations.

Larval development generally occurs in necrotic tissue or at the site of stasis of excretions or secretions in anatomical cavities. In the case we present, myiasis occurred in cutaneous tissue in the absence of infection or other conditions usually required by myiasigenic species.

\section{CLINICAL CASE}

In August 2010 a 75 year old woman was brought to the $\mathrm{S}$. Croce e Carle Hospital from a local nursing home where, during routine care, a nurse had noticed the presence of larvae on the patient's right hand. Her personal physician noted 10 larvae in the webbed space between her thumb and forefinger. They were removed and he referred her to the hospital. Three larvae were set aside in saline solution $(\mathrm{NaCl} 0,9 \%)$ for analysis.

The patient was bedridden and semi-paralyzed following a cerebral hemorrhage 30 months earlier which left her in a pseudo-vegetative state and with total paralysis of her right side. Upon arrival at the hospital her vital signs were stable and her personal hygiene as well as the sanitary conditions of the nursing home were reported as optimal though her room at the facility was well-ventilated via a window which lacked a mosquito-net.

At the site where the parasites were found (Fig. 1) it was possible to see a superficial fissure not longer than $10 \mathrm{~mm}$ (Fig. 2) which had not been noticed during the preceding days' routine care of the patient.

Entomological evaluation of the specimens determined that they were Cyclorrhapha larvae and therefore the case could be classified as myiasis.

The patient was examined by a dermatologist who, in accordance with the entomologist, prescribed disinfecting the fissure followed by the application of antibiotic gentamicin 1\% ointment; a roll of gauze was placed between the thumb and forefinger so that a space could insure further accumulation of sweat which could have resulted in recurrence of the infestation. The temperature of the patient's hands was measured and a significant difference was noted between the two sides: $31.5^{\circ} \mathrm{C}$ (right), $34^{\circ} \mathrm{C}$ (left). After approximately 4 days the patients fissure was completely healed and there were no subsequent infections. The entomologist recommended the installation in the patient's room at the nursing home of a UV-A trap together with a sticky fly trap or a ventilation/capture feature and to further protect her with netting around her bed and/or a screen on the window. Subsequent examination 


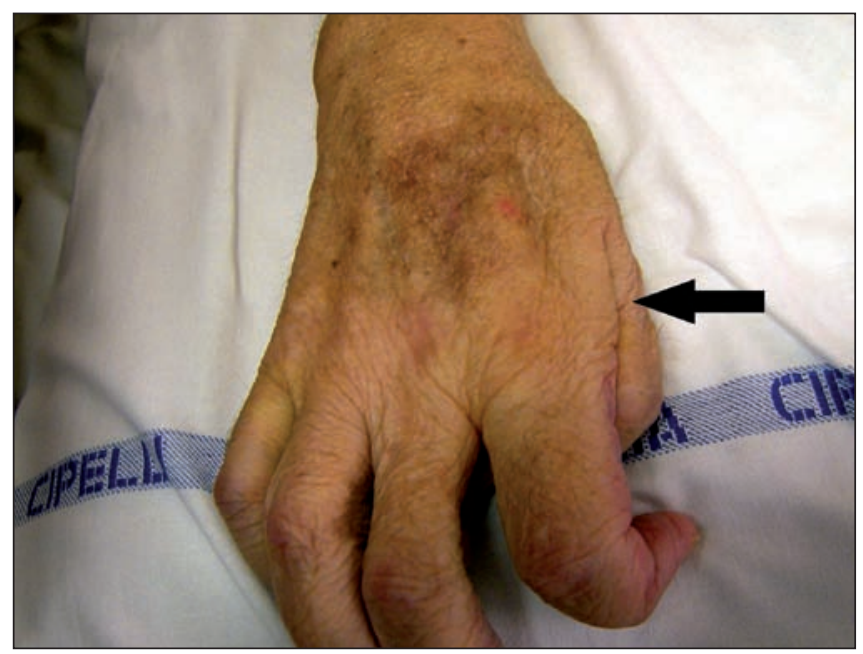

Fig. 1. Photo of limb affected by parasite. The arrow indicates the anatomical cavity parasitized (photo: M. Dutto).

by the patient's personal physician ascertained that there were no larvae present in other areas of her body (auricular, oral, nasal, genital and anal).

The 3 larvae which had been set aside were all confirmed to be second stage (L2). Two were sectioned and the anterior and posterior parts were placed in a solution of potassium hydroxide (KOH 10\%) for 24 hours after which they were placed on slides; the conformation of the respiratory plaques (Fig. 3) and cephalopharyngeal skeletons (Fig. 4) allowed for identification of the larvae as second stage Sarcophaga spp. It was not possible to make a more specific identification due to the lack of identification keys which permit recognition of larvae from the family Sarcophagidae. The third specimen was preserved in ethanol $(\mathrm{ETOH} 70 \% \mathrm{v} / \mathrm{v})$.

\section{CONCLUSIONS}

In our case it is important to note that in absence of the usual features which attract fly species prone to inducing semispecific myiasis (exposed wounds, necrosis, ulcerations, etc.), a female

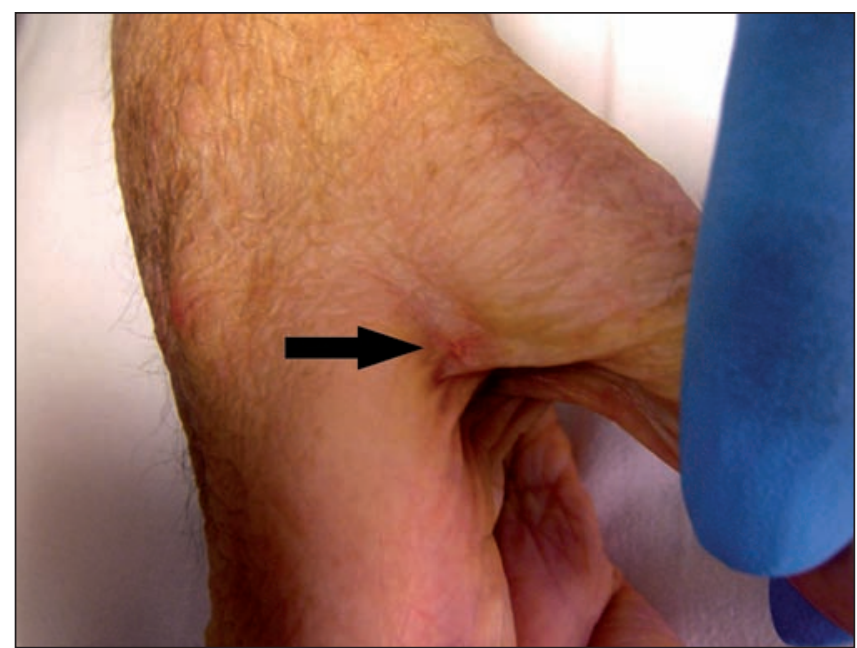

Fig. 2. Webbed space between patient's thumb and forefinger where the larvae were found. The arrow shows the fissure caused by the larvae (photo: M. Dutto).

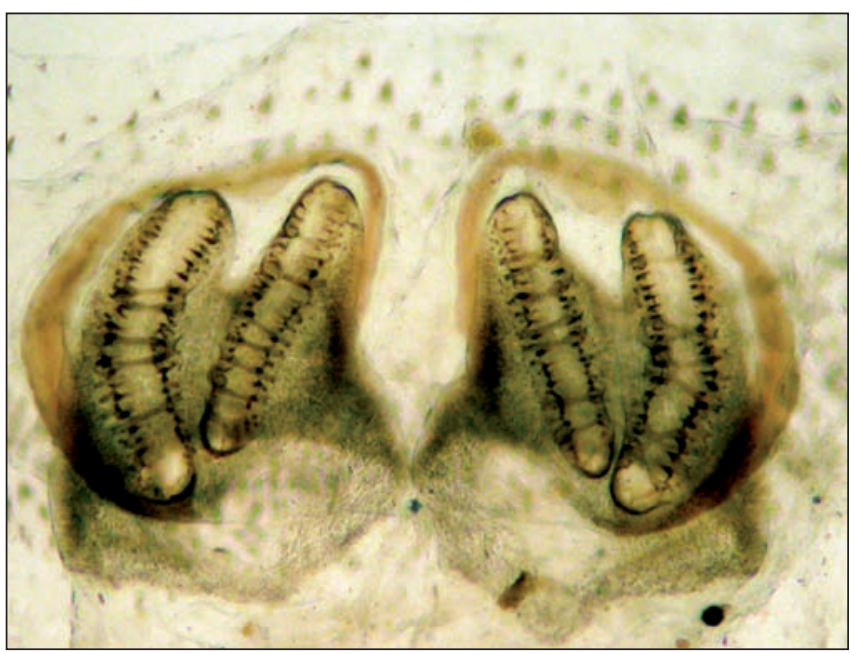

Fig. 3. Respiratory plaques, Sarcophaga spp. larva (photo: M. Dutto).

Sarcophaga laid larvae (L1) in an anatomical cavity lacking a solution of continuity, and the larvae began eroding the epidermis, causing a fissure.

Three factors may have attracted the fly to the patient's hand: maceration of the tissue due to an accumulation of sweat, the below-average temperature of that limb, and the patient's partial paralysis and neuro-vegetative condition.

Analysis of this case leads us to believe that species belonging to the genus Sarcophaga are capable, even in absence of a cutaneous solution of continuity or a significant stasis of fluids or secretions, to initiate myiasis and destroy healthy tissue. The implication is an increase of the parasitic relevance of the genus. An analogous parasitical locus was previously described involving Lucilia however it was in a patient with eczema (16).

Nosocomial myiases can be borne by various obligatory (specific) or facultative (semispecific) parasitic species and are found in various geographic areas $(9,17-21)$; they occur rarely in developed countries and are sparsely represented in the literature, particularly European cases $(9,18,22)$. Factors that predispose nosocomial myiasis are: (i) individuals in a weak and/or debili-

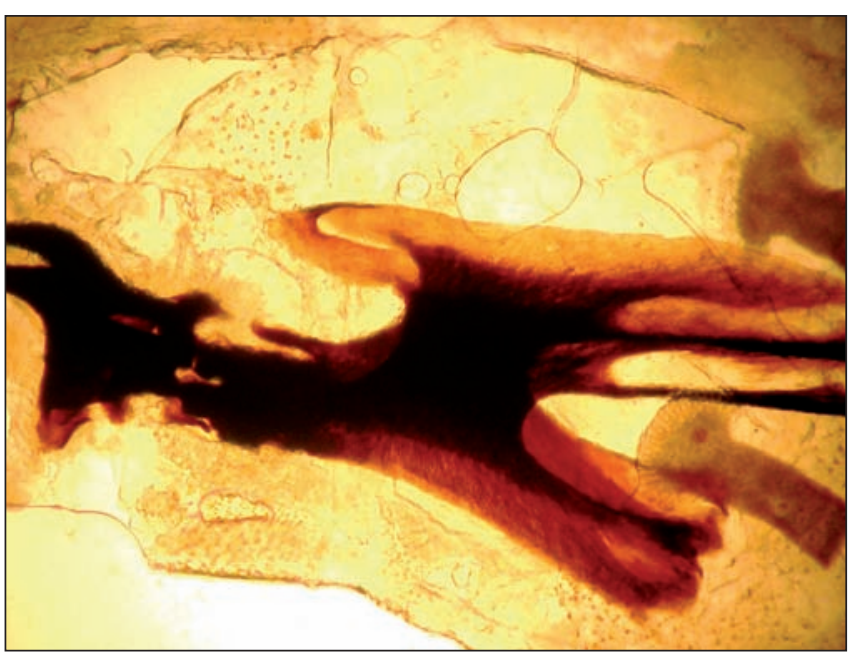

Fig. 4. Cephalopharyngeal skeletons, Sarcophaga spp. larva (photo: M. Dutto). 
tated condition, (ii) the presence of open wounds or necrotized tissue, (iii) inadequate hygiene or nursing care, (iv) absence of screens on windows and (v) summer season.

In order to prevent nosocomial myiases, hospitals and nursing homes should provide screens on windows and install UV-A traps together with a sticky fly traps or a ventilation/capture feature, especially in rooms where there are patients with severe tissue trauma or significant neurological deficit. More complete protection can be offered for high-risk patients in the form of mosquito netting around the patient's bed.

Finally, with regards to myiasis classification, there are currently two types of classification employed: one based on the propensity of a species to induce myiasis (the parasite's specific level of dependency), and one based on the anatomical location of the parasite $(2,23-25)$. The latter is wholly arbitrary and has no taxonomic basis but is of great importance in medical and parasitological settings especially with regards to diagnoses.

The case we have presented is a cutaneous myiasis. Until now cutaneous myiases have been subdivided into furuncular and traumatic myiases. As our case was not clearly one of these two categories, we propose the addition of the term "cutaneous superficial myiasis" to better describe cases such as the one we have reported.

\section{Acknowledgement}

We thank Antonia Schlueter for translating the original Italian text.

\section{REFERENCES}

1. Hope FW. On insects and their larvae occasionally found in the human body. Trans R Entomol Soc. 1840;2:256-71

2. Zumpt F. Myiasis in man and animals in the old world. London: Butterworts; 1965

3. Pasternak J, Joo SH, Ganc AJ, de Souza Durao M, Morsh RD, Pinto TH. A case of throat Cochliomyia hominivorax infestation. Einstein. 2007;5(2):170-2.

4. Safdar N, Young DK, Andes D. Autochthonous furuncular myiasis in the United States: case report and literature review. Clin Infect Dis. $2003 \mathrm{Apr}$ 1;36(7):e73-80.

5. Tligui H, Bouazzaoui A, Agoumi A. Human auricular myiasis caused by Wohlfahrtia magnifica (Diptera: Sarcophagidae): about three observations in Morocco. Bull Soc Pathol Exot. 2007 Feb;100(1):61-4. (In French.)

6. Dutto M. Hygiene and public health: elements of medical and urban entomology and zoology. Torino: C.G. Edizioni Medico-Scientifiche; 2009. (In Italian.)
7. Principato M, Pepe M, Arcelli R, Polidori GA. Myiasis in a dog in Umberia by Sarcophaga haemorrhoidalis (Fallen) (Diptera Sarcophagidae): a fly infection also man. Parassitologia. 1994;36(Suppl.1):117.

8. Das A, Pandey A, Madan M, Asthana AK, Gautam A. Accidental intestinal myiasis caused by genus Sarcophaga. Indian J Med Microbiol. 2010 Apr-Jun;28(2):176-8.

9. Dutto M, Bertero M. Traumatic myiasis from Sarcophaga (Bercaea) cruentata Meigen, 1826 (Diptera, Sarcophagidae) in a hospital environment: reporting of a clinical case following polytrauma. J Prev Med Hyg. 2010 Mar;51(1):50-2.

10. Hokelek M, Akbas H, Guneren E, Eroglu L, Eroglu C, Acici M, et al. Myiasis infestation: a rare complications of decubitus ulcer. Eur J Plast Surg. 2002;25(1):32-4.

11. Braverman I, Dano I, Saah D, Gapany B. Aural myiasis caused by flesh fly larva, Sarcophaga haemorrhoidalis. J Otolaryngol. 1994 Jun;23(3):204-5.

12. Erfan F. Gingival myiasis caused by Diptera (sarcophaga). Oral Surg Oral Med Oral Pathol. 1980 Feb;49(2):148-50.

13. Razmjou H, Mowlavi GH, Nateghpour M, Solaymani-Mohamadi S, Kia EB. Ophthalmomyiasis caused by Flesh Fly (Diptera: Sarcophagidae) in a patient with eye malignancy in Iran. Iran J Arthropod Borne Dis. 2007;1(2):53-6.

14. Türk M, Afşar I, Ozbel Y, Sener AG, Uner A, Türker M. A case of nasomyiasis whose agent was Sarcophaga sp. Turkiye Parazitol Derg. 2006;30(4):330-2.

15. Passos MR, Carvalho AV, Dutra AL, Goulart Filho RA, Barreto NA, Salles RS, et al. Vulvar myiasis. Infect Dis Obstet Gynecol. 1998;6(2):69-71.

16. Leclercq M. The myiases. Annls Soc Ent Fr. 1990;26(3):335-50. (In French.)

17. Hira PR, Assad RM, Okasha G, Al-Ali FM, Iqbal J, Mutawali KE, et al. Myiasis in Kuwait: nosocomial infections caused by lucilia sericata and Megaselia scalaris. Am J Trop Med Hyg. 2004 Apr;70(4):386-9.

18. Mielke U. Nosocomial myiasis. J Hosp Infect. 1997 Sep;37(1):1-5.

19. Szakacs TA, MacPherson P, Sinclair BJ, Gill BD, McCarthy AE. Nosocomial myiasis in a Canadian intensive care unit. CMAJ. 2007 Sep 25;177(7):719-20.

20. Yazar S, Dik B, Yalçin S, Demirtaș F, Yaman O, Oztürk M, et al. Nosocomial Oral Myiasis by Sarcophaga sp. in Turkey. Yonsei Med J. 2005 Jun 30;46(3):431-4.

21. Joo CY, Kim JB. Nosocomial submandibular infections with dipterous fly larvae. Korean J Parasitol. 2001 Sep;39(3):255-60.

22. Minar J, Herold J, Eliskova J. Nosocomial myiasis in Central Europe Epidemiol Mikrobiol Immunol. 1995;44(2):81-3. (In Czech.)

23. James MT, Maslin TP. Notes on myiasis of the toad, Bufo boreas boreas Baird and Girard. J Wash Acad Sci. 1947 Oct 15;37(10):366-8.

24. Kettle DS. Medical and veterinary entomology. London: Croom Helm; 1984.

25. Patton WS. Notes on the myiasis producing Diptera of man and animals. Bull Entomol Res. 1922;12:239-61. 